\title{
Efficacy of Intravenous Immunoglobulin in Neurological Diseases
}

\author{
Jan D. Lünemann ${ }^{1,2}$ • Isaak Quast ${ }^{1}$ - Marinos C. Dalakas ${ }^{3,4}$
}

Published online: 23 September 2015

(C) The American Society for Experimental NeuroTherapeutics, Inc. 2015

\begin{abstract}
Owing to its anti-inflammatory efficacy in various autoimmune disease conditions, intravenous immunoglobulin (IVIG) - pooled IgG obtained from the plasma of several thousands individuals - has been used for nearly three decades and is proving to be efficient in a growing number of neurological diseases. IVIG therapy has been firmly established for the treatment of Guillain-Barré syndrome, chronic inflammatory demyelinating polyneuropathy, and multifocal motor neuropathy, either as first-line therapy or adjunctive treatment. IVIG is also recommended as rescue therapy in patients with worsening myasthenia gravis and is beneficial as a second-line therapy for dermatomyositis and stiff-person syndrome. Subcutaneous rather than intravenous administration of $\operatorname{IgG}$ is gaining momentum because of its effectiveness in patients with primary immunodeficiency and the ease with which it can be administered independently from hospital-based infusions. The demand for IVIG therapy is growing, resulting in rising costs and supply shortages. Strategies to replace IVIG with
\end{abstract}

Jan D. Lünemann

jan.luenemann@uzh.ch

1 Institute of Experimental Immunology, Laboratory of Neuroinflammation, University of Zürich, Winterthurerstrasse 190, Zürich, Switzerland

2 Department of Neurology, University Hospital of Basel, Basel, Switzerland

3 Neuroimmunology Unit, University of Athens Medical School, Athens, Greece

4 Department of Neurology, Thomas Jefferson University, Philadelphia, PA, USA recombinant products have been developed based on proposed mechanisms that confer the anti-inflammatory activity of IVIG, but their efficacy has not been tested in clinical trials. This review covers new developments in the immunobiology and clinical applications of IVIG in neurological diseases.

Keywords Intravenous immunoglobulin · Immunotherapy · Neurology

\section{Introduction}

The success story of the clinical application of pooled IgG preparations from thousands of donors, so-called intravenous IgG (IVIG) therapy, to patients with autoimmune disease conditions began more than 30 years ago. In 1980, Imbach et al. [1] started the first IVIG administration at an empirical dose of $0.4 \mathrm{~g} / \mathrm{kg}$ bodyweight as a replacement therapy in a boy with immune thrombocytopenia (ITP) and secondary hypogammaglobulinemia due to long-term immunosuppressive treatment. After the first administration of IVIG, his platelet counts dramatically increased and IVIG therapy was continued at the same dose for a total of 5 days. Twelve consecutive children with ITP but without hypogammaglobulinemia showed the same phenomenon [1]. Later studies confirmed these results in adult patients with ITP, initiating the widespread use of IVIG preparations as an immunomodulatory therapy for the treatment of other autoimmune diseases [2].

Today, IVIG therapy is used in the treatment of a wide variety of diseases, with $>75 \%$ of the IVIG in the USA administered to patients with autoimmune or inflammatory conditions [3]. The Food and Drug Administration (FDA)-approved indications for immune globulin therapy are limited, but a large number of diseases, especially those seen by 
neurologists, have shown potentially beneficial responses to IVIG. Based on controlled clinical trials IVIG is now recognized as first-line therapy in patients with Guillain-Barré syndrome (GBS), chronic inflammatory demyelinating polyneuropathy (CIDP), and multifocal motor neuropathy $(\mathrm{MMN})$. It is an effective rescue therapy in some patients with worsening myasthenia gravis (MG) and beneficial as secondline therapy in patients with dermatomyositis and stiff-person syndrome [4]. Despite its widespread use and broad efficacy, the mechanisms that confer the anti-inflammatory or immunomodulating activity in autoimmune disease conditions are poorly understood. This review provides on overview of the immunobiology of the proposed mechanisms of action of IVIG and its clinical efficacy in neurological diseases.

\section{Immunobiology of IVIG}

The production of IVIG follows the general guidelines established by the International Union of Immunological Societies and the World Health Organization. The source material should be plasma obtained from a pool of at least 1000 donors. Final products should be free of any potentially harmful contaminants, which includes testing for HIV 1 and 2, hepatitis $\mathrm{C}$ virus antibodies, hepatitis $\mathrm{B}$ surface antigen, and high titers of $\mathrm{ABO}$ antibodies, to reduce the risk for hemolytic reactions. The levels of IgG complexes and concentrations of IgA should be kept to a minimum to avoid overt immune stimulation and anaphylactic reactions in patients with $\operatorname{IgA}$ deficiency and anti-IgA antibodies, respectively. The final product should contain at least $90 \%$ intact IgG and subclasses should be present in similar proportions to those in normal blood plasma. There are 4 subclasses in humans (IgG1, $\mathrm{IgG} 2$, IgG3, and IgG4), named in order of their abundance in serum, with IgG1 being the most abundant (60-70\%) followed by IgG2 (20\%), IgG3 (7\%), and IgG4 (3\%). These subclasses differ in their ability to induce complement activation (IgG3 > IgG1 > IgG2) and their affinity for IgG-Fc receptors $(\operatorname{IgG} 1>\operatorname{IgG} 3>\operatorname{IgG} 4>\operatorname{IgG} 2)$.

IgG molecules are glycoproteins that can be divided into 2 functional components: 1) the C-terminal immunoglobulin domains $\mathrm{CH} 3$ and $\mathrm{CH} 2$ of the antibody heavy chain constitute the "fragment crystallizable" (Fc) domain; and 2) the Nterminal $\mathrm{CH} 1$ and $\mathrm{VH}$ domains together with the antibody light chain constitute the "fragment antigen binding" domain (Fab) (Fig. 1A). These 2 domains are joined by hinge regions providing flexibility to the antibody. Fab domains contain highly variable "complementarity determining regions", which are responsible for antigen recognition. The purpose of the $\mathrm{Fc}$ region is to provide stability to the antibody and to combine the specificity of the Fab with cellular and humoral effector mechanisms.
IgG has evolved to fulfill its functions using many mechanisms of the immune systems, which, in turn, requires a broad spectrum of regulatory mechanisms to tightly control and coordinate the properties of IgG. This is mainly achieved by structural diversification of the Fc resulting either from the usage of 1 of the 4 distinct IgG isotypes or by alteration of the Fc-linked glycan (Fig. 1B). The Fc-linked glycan comprises a single, highly conserved canonical glycosylation motif present in both of the $2 \mathrm{Fc}$ polypeptide chains, each of which is composed of a nonvariable structure consisting of 2 $\mathrm{N}$-acetylglucosamine residues followed by 3 branched mannose residues. The vast majority of glycans also contain $\mathrm{N}$ acetylglucosamine on the alpha 1-3 and alpha 1-6 arm, and a small fraction additionally contains a so-called bisecting $\mathrm{N}$ acetylglucosamine on the alpha 1-4 arm. The presence of the core heptasaccharide is a key component for antibody functionality and essential for IgG to pass post-translational quality control. In contrast, the presence or absence of fucose, terminal galactose, and sialic acid on the glycan is not essential and can therefore be used by the immune system to finetune effector functions of IgG.

Receptors binding the $\mathrm{Fc}$ region of $\mathrm{IgG}$, so called $\mathrm{Fc}$ gamma-receptors (Fc $\gamma \mathrm{Rs}$ ) are crucial in mediating the effector functions of antibodies. Traditionally, these receptors are divided into 2 groups, based on their activating or inhibitory properties reflected by the presence of either immune thyrosininhibitory molecule or immune thyrosin-activating molecule sequences in their intracellular domain or their signaling adaptor molecules (Fig. 2). The receptor's affinity for IgG determines whether IgG binds in a monomeric form and cells expressing the respective Fc $\gamma \mathrm{R}$ are therefore constantly associated with surface-bound antibodies, or only bind if the avidity is increased by the recognition of an antigen and the formation of an immune complex. Monocytes, macrophages, and dendritic cells (DCs) express several Fc $\gamma$ Rs on their cell surface and can co-express activating Fc $\gamma$ Rs (Fc $\gamma$ RI, Fc $\gamma$ RIIA(C) Fc $\gamma$ RIIIA) with the inhibitory Fc $\gamma$ RIIB. Relative expression levels of activating versus inhibitory receptors have been shown to influence the response towards immune complexes and set the threshold for DC activation [5]. In addition to its function in myeloid cells, Fc $\gamma$ RIIB negatively regulates signaling via the B-cell receptor complex, resulting in decreased antigeninduced proliferation and antibody production [6, 7]. Its expression on plasma cells controls their persistence in the bone marrow [8], while deletion of Fc $\gamma$ RIIB leads to increased frequencies of autoreactive plasma cells [9]. Fc $\gamma$ RIIIA is the main $\mathrm{F} c \gamma \mathrm{R}$ found on natural killer cells, where it is essential for the lysis of tumor or virus-transformed cells by antibodydependent cell-mediated cytotoxicity.

Fc-receptors also contribute to the long half-life of IgG antibodies of approximately 21 days for the most abundant subclasses IgG1 and $\operatorname{IgG} 2$. The neonatal FcR ( $\mathrm{FcRn}$ ), similar in structure to major histocompatibility complex class I 
Fig. 1 Structure of $\operatorname{IgG}$ and its Fc-linked glycans. (A) Schematic depiction of a prototypic IgG1 antibody composed of 2 heavy and light chains and 2 glycans. Structural and functional components are indicated in gray. $\mathrm{Fab}=$ fragment antigen binding; $\mathrm{Fc}=$ fragment crystallizable; $\mathrm{C}_{\mathrm{H}}=$ constant domain heavy chain; $\mathrm{C}_{\mathrm{L}}$ $=$ constant domain light chain; $\mathrm{V}_{\mathrm{H}}$ $=$ variable domain heavy chain; $\mathrm{V}_{\mathrm{L}}=$ variable domain light chain. (B) Composition of a fully processed N297-glycan (galactosylated, sialylated, and containing a bisecting $N$ acetylglucosamine)

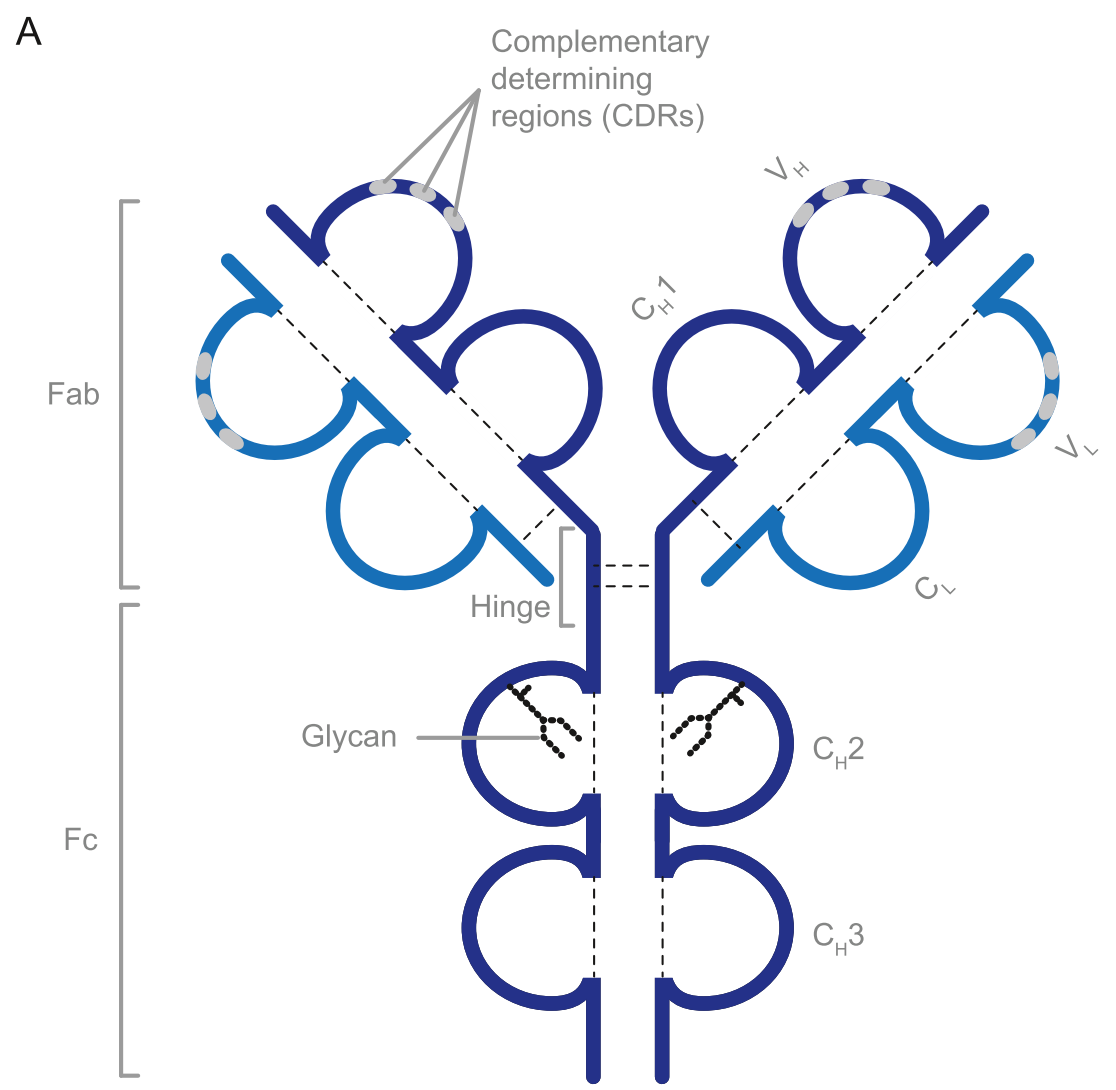

B

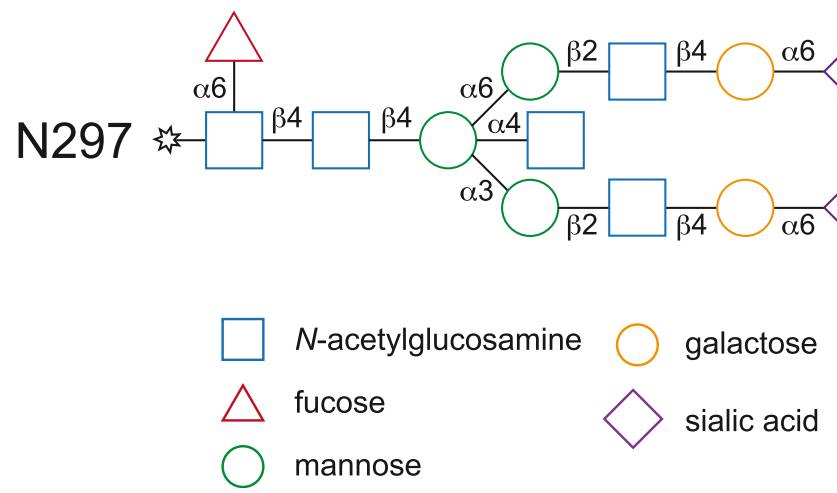

molecules, cycles between the cell surface and acidic endosomal compartments where a low $\mathrm{pH}$ allows its binding to internalized IgG (Fig. 2). FcRn-IgG complexes are then transported back to the cell surface and physiological $\mathrm{pH}$ leads to subsequent dissociation of the FcRn-IgG complex [10]. This process increases the half-life of IgG molecules up to 5-fold $[11,12]$.

\section{Potential Mechanisms of IVIG Efficacy}

IVIG preparations contain antibodies directed against a broad range of pathogens, as well as against numerous foreign and self antigens. Based on the architecture of their Fc domain, antibodies differ in their ability to induce Fcmediated effector functions, such as activation of innate immune cells via Fc receptor binding or complement activation, as discussed above. Given the heterogeneity of the various autoimmune disease conditions that respond to IVIG, it seems likely that different disease-specific pathways mediate the clinical efficacy of this agent for a given disease. Hence, it has been difficult to identify a general mechanism for the anti-inflammatory or immunomodulating efficacy of IVIG. Potential mechanisms identified so far have mainly been attributed to the $\mathrm{F}\left(\mathrm{ab}^{\prime}\right)_{2}$ domain, the $\mathrm{Fc}$ domain, and/or the Fc-linked $\mathrm{N}$-glycan. 


\section{$\mathbf{F}\left(\mathbf{a b}^{\prime}\right)_{2}$-mediated Mechanisms}

An example for $\mathrm{F}\left(\mathrm{ab}^{\prime}\right)_{2}$-mediated mechanisms, Fas-FasL (also called CD95-CD95L) receptor-ligand mediated apoptosis of keratinocytes, an early morphologic feature in patients with toxic epidermal necrolysis (Lyell syndrome), was shown to be inhibited by blockade through CD95-binding antibodies in IVIG preparations, and patients with toxic epidermal necrolysis showed a clinical benefit from IVIG therapy [13]. Additional specificities found in IVIG and implicated as potentially important therapeutic targets are anti-idiotype antibodies that might neutralize pathogenic antibodies such as glycolipid-specific antibodies in GBS or acetylcholine receptor-targeting antibodies in patients with MG [14-17]. Moreover, the presence of antibodies against T-cell receptors within IVIG preparations might shape the T-cell repertoire during inflammatory responses [18].

\section{Fc-mediated Mechanisms}

Unlike $\mathrm{F}\left(\mathrm{ab}^{\prime}\right)_{2}$-mediated anti-inflammatory properties, which have so far only been demonstrated in vitro or in animal models, a clinical trial demonstrated that infusion of Fc fragments alone is an efficient treatment of acute ITP in children [19], suggesting that the beneficial clinical effects of IVIG in ITP are Fc-mediated. Potential mechanisms include Fc $\gamma \mathrm{R}$ blocking [20], modulation of Fc $\gamma \mathrm{R}$ expression and signaling $[21,22]$, increased autoantibody clearance by FcRn saturation [23], suppression of immunoglobulin production [24], modulation of antigen-presenting cell activation by induction of inhibitory Fc $\gamma$ RIIB [25], and blockade of complement proteins $[26,27]$. Other potential mechanisms are induction of regulatory $\mathrm{T}$ cells by peptide sequences called "tregitopes" contained within the IgG constant regions [28], and inhibition of differentiation and maturation of dendritic cells [29].

The presence of sialic acid in IgG Fc glycans has also been implicated in mediating the anti-inflammatory properties of IVIG. The significance of IgG glycosylation is highlighted by the loss of therapeutic activity of deglycosylated IVIG preparations [30]. Conversely, IVIG preparations, as well as isolated Fc fragments enriched for terminal sialic acid residues, have a more than 10-fold higher anti-inflammatory activity in an antibodymediated animal model of rheumatoid arthritis $(\mathrm{K} / \mathrm{BxN}$ model $)$ $[30,31]$. The requirement of sialic acid for the protective effect of IVIG was confirmed for several but not all autoimmune disease models investigated [32-35].

\section{Clinical Efficacy of IVIG in Neurological Diseases}

A number of randomized controlled trials have shown that IVIG is effective in acute and chronic demyelinating neuropathies, in worsening MG as short-term therapy, in certain inflammatory myopathies, and in stiff-person syndrome (Table 1). In large number of case series but not controlled studies, IVIG is also promising in treating various neuroinflammatory, painful, or even neurodegenerative disorders. For these diseases, however, the use of IVIG is largely "off-label", even when efficacy has been established with randomized trials. As a result, and because of the high cost or at times unwise use, insurance carriers, healthcare organizations, and government agencies many times do not approve IVIG therapy, even for disorders where there is evidence-based efficacy or approved indications. A judicious use of the drug is therefore necessary, with periodic assessments of its continuous effectiveness to avoid unnecessary use or overtreatment,

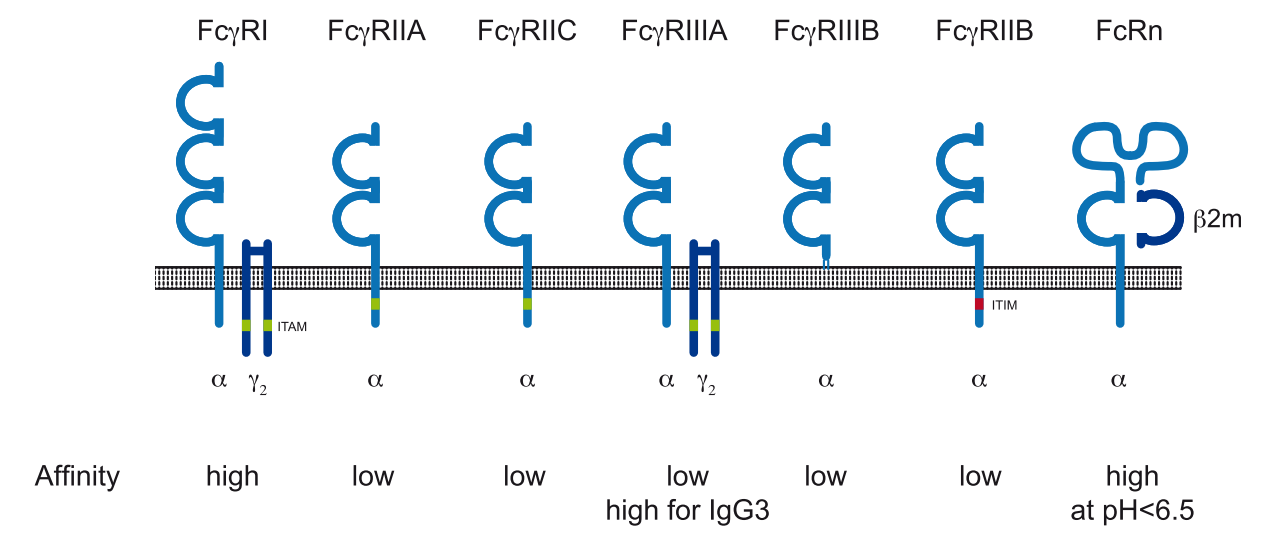

\section{Function}

Fig. 2 The human Fc $\gamma$ R family. Schematic depiction of human Fc $\gamma$ Rs $\alpha$-chains and the major signaling adaptor molecule for Fc $\gamma \mathrm{RI}$ and Fc $\gamma$ RIIIA, the common gamma chain dimer $\left(\gamma_{2}\right)$. Immune tyrosinebased activation (ITAM, green) or inhibition (ITIM, red) sequences are indicated. FcRn is a heterodimeric major histocompatibility chain-I like molecule associated with $\beta 2$ microglobulin $(\beta 2 \mathrm{~m})$. The receptor's affinity for $\mathrm{IgG}$ and their function in upon receptor cross-linking are indicated 
Table 1 Efficacy of intravenous IgG in neurological diseases: evidence from clinical trials

\begin{tabular}{|c|c|}
\hline Indication & Level of evidence \\
\hline Guillain-Barré syndrome & Class I \\
\hline $\begin{array}{l}\text { Chronic inflammatory } \\
\text { demyelinating } \\
\text { polyneuropathy }\end{array}$ & Class I \\
\hline Multifocal motor neuropathy & Class I \\
\hline Myasthenia gravis & $\begin{array}{l}\text { Class I for short term efficacy; } \\
\text { long-term efficacy has not } \\
\text { been established }\end{array}$ \\
\hline Dermatomyositis & Class I \\
\hline Stiff-person syndrome & Class I \\
\hline Polymyositis & Class IV \\
\hline Neuromyelitis optica & Class IV \\
\hline Autoimmune encephalitis & Class IV \\
\hline Reflex sympathetic dystrophy & Class IV \\
\hline $\begin{array}{l}\text { Necrotizing autoimmune } \\
\text { myositis }\end{array}$ & Class IV \\
\hline Multiple sclerosis & Class I (not effective) \\
\hline Alzheimer disease & Class I (not effective) \\
\hline $\begin{array}{l}\text { Anti-MAG paraproteinemic } \\
\text { neuropathy }\end{array}$ & Class I (not effective) \\
\hline Inclusion body myositis & Class I (not effective) \\
\hline Postpolio syndrome & $\begin{array}{l}\text { Class I for short-term efficacy } \\
\text { (not effective) }\end{array}$ \\
\hline
\end{tabular}

$M A G$ myelin-associated glycoprotein

as discussed [36]. However, as clinicians, we need to have an open mind to help patients with autoimmune neurological syndromes that do not always fit into a predefined or restricted category for which there is an approved indication. In such circumstances, if a patient does not demonstrate any objective clinical benefit after 2-3 infusions, it is unlikely that IVIG will be useful and should not be continued to avoid unwise use and unnecessarily high cost. The diseases in which IVIG has been tested in controlled trials include the following.

\section{GBS}

Based on at least 2 randomized trials, one dose of IVIG (5-day regimen of $0.4 \mathrm{~g} / \mathrm{kg} / \mathrm{day}$ ) was comparable to plasmapheresis $(\mathrm{PE})$ in outcome measures, including time to unaided walking and discontinuation of ventilation (class I evidence) [37, 38]. Combining IVIG with PE or with $500 \mathrm{mg}$ intravenous methylprednisone produces no incremental response. In GBS variants, such as the acute axonal motor or motor sensory forms, Miller-Fisher syndrome, or acute dysautonomia, IVIG appears to be helpful, but controlled studies have not been conducted. IVIG remains the treatment of choice in childhood GBS, based on observations attesting to a faster recovery and reduced morbidity, but controlled studies are not available and may never be conducted. In mechanically ventilated children, however, PE may be superior to IVIG [39]. Whether a second IVIG infusion may offer additional benefit when improvement has either not occurred or is inadequate 3 weeks after the first infusion, remains unclear in spite of anecdotal evidence [40]. Because a small increase in serum IgG level 2 weeks after a single IVIG infusion was independently associated with a significantly slower recovery and more disability at 6 months [41], a low $\Delta \operatorname{IgG} 2$ weeks after the initial infusion was considered a sign that a higher dosage or a second course may be helpful for patients who exhibit poor outcome. On this basis, a controlled study assessing the benefit of a second IVIG infusion is currently ongoing.

\section{CIDP}

Controlled studies have shown that steroids, PE, and IVIG are equally effective on a short-term basis [42-44]. The ICE trial, the largest ever conducted in CIDP, has showed that IVIG is safe and effective not only in the short term, but also in the long term, leading to the first FDA-approved indication for a brand of IVIG (class I evidence) [45]. A strong and positive effect on quality of life and improvement in some electrophysiological measurements were also noted [46, 47]. In most patients, IVIG becomes effective after 6 weeks, necessitating the need for at least 2 infusions before it can be concluded that IVIG is ineffective [48]. Although IVIG is generally considered as first-line therapy, based on the ICE trial, the choice of how best to initiate therapy (choosing between prednisone, IVIG, or PE, which are all effective in controlled trials) is judged against cost, long-term side effects, patient age, venous access, disease severity, and concurrent illnesses. In practice, we have also noticed, for reasons that still remain unclear, that some patients respond predominantly to IVIG, others to prednisone, and still others to PE. Patients more likely to respond to IVIG appear those with disease duration $<1$ year, a relapsing course, and electrophysiological signs of demyelination with conduction block [49, 50]. At the molecular level, single nucleotide polymorphisms corresponding to transient axonal glycoprotein 1 were significantly associated with improvement from IVIG [51], suggesting that, if confirmed, responsiveness to IVIG may be genetically determined. Fc $\gamma$ RIIB expression was reported to be decreased in treatment-naïve patients with CIDP and upregulated upon clinically effective IVIG therapy [21], suggesting that the effect on Fc $\gamma$ RIIB may be a factor predicting the patients more likely to respond to IVIG. Further, the effect of IVIG on glycosylation of immunoglobulin and Fc $\gamma$ RIIB is currently being explored as a potentially biomarker predicting IVIG responsiveness.

\section{MMN}

Unlike CIDP and GBS, MMN does not respond to steroids or PE, only to IVIG. Efficacy has been established with a number 
of controlled trials [52-54]. As a result, regulatory agencies in the US approved the IVIG product from Baxter (Deerfield, IL, USA) for the treatment of MMN. The improvement lasts from 3 to 6 weeks, requiring reinfusion at almost predictable time periods. As symptoms diminish, the electrophysiologic conduction block may resolve [53]. Therapy starts with $2 \mathrm{~g} / \mathrm{kg}$ but the response can be maintained with $1 \mathrm{~g} / \mathrm{kg}$.

\section{Other Neuropathies}

IVIG has been unsuccessful in anti-myelin-associated glycoprotein demyelinating, neuropathy based on 2 controlled trials $[55,56]$. It has been anecdotally tried in diabetic amyotrophy $[57,58]$, vasculitic neuropathy [59], and in some painful sensory neuropathies, such as those associated with Sjögren syndrome [60], with variable results. At this point, the evidence of efficacy is overall insufficient to earn recommendation for use of IVIG in any of these conditions.

\section{MG}

The use of IVIG in MG has been examined in randomized trials for treating exacerbations in lieu of plasmapheresis. In 2 randomized trials, IVIG was as effective as plasmapheresis at day 15 [61]. In one of the studies [62], there was no difference between patients randomized to $1 \mathrm{~g} / \mathrm{kg}$ for 1 day versus $2 \mathrm{~g} / \mathrm{kg}$ for 2 days. IVIG was also superior to placebo, 14 days after therapy, in patients with moderate-to-severe MG and "worsening weakness" [63]. Although IVIG may be effective on a short-term basis, its role in the chronic management of the disease or as a steroid-sparing drug has not yet been established [64] necessitating 2 ongoing trials, the first to establish long-term efficacy and the second to explore the steroid-sparing effect. The efficacy of IVIG has also not been tested in seronegarive or muscle-specific tyrosine kinasepositive MG. At present, IVIG may be justified in lieu of plasmapheresis for acutely worsening disease to prevent or minimize impending bulbar or respiratory failure or prepare a weak patient for thymectomy. IVIG may be also effective in Lambert-Eaton myasthenic syndrome, based on a small placebo-controlled study that showed a statistically significant increase in muscle strength compared with placebo, 2-4 weeks after therapy [65].

\section{Inflammatory Myopathies}

They comprise 4 subsets: dermatomyositis, polymyositis, inclusion body myositis, and necrotizing autoimmune myositis. In a double-blind, placebo-controlled study conducted in dermatomyositis, compared with those treated with placebo, the patients treated with IVIG experienced a significant improvement in strength and muscle function, and a marked improvement of the active rash or the chronic scaly eruptions [66].
Repeat muscle biopsies demonstrated significant improvement in the muscle cytoarchitecture, including increased muscle fiber diameter, revascularization, reduction of inflammation, interception of complement deposition, resolution of immunopathology, and downregulation of inflammatory mediators at the protein, mRNA, and gene level [67-70]. This study was important to demonstrate that an effective action of IVIG is via inhibition of complement. In dermatomyositis, early deposition of membranolytic attack complex on the endomysial capillaries is the fundamental process leading to capillary destruction, muscle ischemia, and inflammation. In improved patients, IVIG inhibited complement consumption in serum and intercepted the complement-mediated destruction of capillaries with resolution of immunopathology. IVIG seems effective in some patients with polymyositis and necrotizing autoimmune myositis [71, 72], but a controlled study has never been performed. IVIG is ineffective in inclusionbody myositis, based on 2 controlled studies [68, 73, 74]. Combination of IVIG with prednisone was also ineffective and did not exert a synergistic effect in patients with inclusion-body myositis [75]. The reason for such inefficacy was recently explored in the repeated biopsies of these patients and found that while there was downregulation in the expression of some inflammatory molecules in the patients' muscles, several crucial markers of inflammation, cell stress, and degeneration remain unchanged [76].

\section{Stiff-person Syndrome}

Stiff-person syndrome is a disabling autoimmune disorder characterized by muscle rigidity, episodic muscle spasms, and antibodies to glutamic acid decarboxylase 65 [77]. In a placebo-controlled, crossover study [78], IVIG significantly decreased stiffness scores, and substantially increased walking and functions of daily activities, concluding that IVIG is an effective immunotherapy in stiff-person syndrome.

\section{Multiple Sclerosis}

Two initial randomized, double-blind, placebo-controlled clinical trials in patients with relapsing-remitting multiple sclerosis (MS) demonstrated that IVIG treatment reduces the exacerbation rate and clinical progression, as defined by the expanded disability status score, over an observation period of 2 years [79, 80]. However, subsequent multicenter randomized, double-blind, placebo-controlled clinical trials did not confirm these findings. As an add-on treatment to methylprednisolone, IVIG did not further ameliorate MS relapses [81, 82]. No significant reduction of relapse rate and expanded disability status score progression was observed in patients with relapsing-remitting MS compared with those receiving placebo [83]. In secondary progressive MS, compared with placebo, IVIG had no beneficial effects on clinical disease 
progression or T2-lesion load [84]. These divergent results on the efficacy of IVIG in MS might result from differences in study populations, dosing regimens, and clinical trial design, but led to the conclusion that IVIG is ineffective and not recommended for patients with relapsing-remitting or secondary progressive MS. However, a retrospective study that explored safety and efficacy of IVIG in pregnant women with MS showed that IVIG therapy during pregnancy until 12 weeks postpartum significantly reduced the frequency of MS exacerbations compared with untreated patients [85, 86]. Based on these findings and owing to safety concerns with currently licensed MS drugs during pregnancy and lactation, IVIG is occasionally considered as an optional treatment to reduce the incidence of pregnancy-related or postpartum relapses.

\section{Novel Applications}

\section{Neuromyelitis Optica}

Neuromyelitis optica (Devic syndrome), long considered a clinical variant of MS, is now regarded as a distinct clinical entity. In a retrospective study, IVIG was described to be effective in some patients who experienced acute relapses and did not benefit from steroids or plasma exchange therapy [87], and might also be effective as long-term treatment [88]. While these data suggest that IVIG therapy could be an alternative for patients with contraindication to immunosuppressive prophylactic treatments such as azathioprine and rituximab or, particularly, in children, randomized controlled trials are needed to establish the efficacy of IVIG for treatment of relapses and prevention of disease progression in patients with this condition.

\section{Autoimmune Encephalitis}

Autoimmune encephalitis comprises an expanding group of potentially treatable disorders that occurs in association with antibodies to neuronal cell surface or synaptic proteins. In case series, but not controlled studies, patients with these conditions have been shown to benefit from IVIG therapy, as well as from corticosteroids and plasma exchange, but they often require more aggressive, immunosuppressive therapies with rituximab or cyclophosphamide [89].

\section{Postpolio Syndrome}

This is clinically characterized by new muscle weakness, fatigue, and pain that develop many years after an initial attack of acute paralytic poliomyelitis. It is thought to be due to attrition of the surviving motor neurons [90]. Lymphocytic infiltrates in the spinal cords of have, however, been observed even 30 years after the original infection, and upregulation of RNA for tumor necrosis factor, interferon- $\gamma$, interleukin- 4 , and interleukin-10 has been observed in the cerebrospinal fluid (CSF), suggesting the possibility of a persistent smoldering inflammatory response. Following IVIG treatment, interferon- $\gamma$ and tumor necrosis factor mRNA levels were reduced in the CSF, prompting a controlled trial performed in 135 patients. Although the results were essentially negative, some significant differences, of uncertain clinical importance, were observed in some physical activity and quality-of-life scores [91]. On this basis, a new FDA-approved multicenter clinical trial has started and is currently ongoing.

\section{Reflex Sympathetic Dystrophy}

In the pathogenesis of reflex sympathetic dystrophy and other chronic pain syndromes, proinflammatory cytokines, or antibodies to potassium channels have been implicated. On this basis, IVIG has been tried, with variable results [92]. In a randomized, double-blind, placebo-controlled crossover trial the efficacy of low-dose IVIG $0.5 \mathrm{~g} / \mathrm{kg}$ was examined in 12 patients 6-19 days after IVIG. Although a reduction in pain scales was noted, the study was too small to conclude on the overall efficacy of IVIG not only in RSD, but also in other pain syndromes. However, the concept is of interest and requires vigorously controlled large-scale trials.

\section{The Emerging Role of Subcutaneous IgG}

The subcutaneous route of administering IgG, instead of intravenously, is gaining momentum because of its effectiveness in primary immunodeficiency and ease of self-administration at home on a weekly basis. Subcutaneous IgG (SCIG) is also well tolerated, can be used in patients with poor venous access, has fewer systemic side effects, and is probably less costly. As a result, a number of controlled studies are emerging in CIDP, MMN, and dermatomyositis, especially with new high-concentration products that allow the self-infusion of high IgG quantities. In a small CIDP trial, 30 patients were randomized to SCIG or placebo at home. After 12 weeks, the SCIG group had a statistically improved strength and stability of electrophysiology compared with placebo [93]. Large-scale controlled studies are ongoing, examining the safety, formula of transitioning from IVIG to SCIG, and efficacy and patients' preference.

\section{Pharmacokinetics of IVIG versus SCIG}

An infusion of $2 \mathrm{~g} / \mathrm{kg}$ IVIG increases the serum IgG level $>4$-fold, from pretreatment means of $700-1060 \mathrm{mg} / \mathrm{dl}$ to a peak well over $3000 \mathrm{mg} / \mathrm{dl}$ [94], dropping to about $50 \%$ over $48-72 \mathrm{~h}$. The infused IgG is also seen in the CSF, 
where it peaks by 2 days to almost twice the baseline [95]. The infused IVIG is distributed in the extracellular space, which is about double the intravascular space [96]; it is then catabolized slowly compared with other plasma proteins via FcRn, which recycles IgG and protects it from lysosomal degradation [97]. As a result, the half-life of IgG is maintained at approximately 21 days, and repeated infusions are needed after 1 month. The saturation of the FcRn with high concentrations of normal IgG from the infused exogenous IVIG keeps the endogenous pathologic IgG from this pathway and increases its degradation [98]. In contrast, SCIG is first transported through the lymphatic systems and enters the bloodstream via the thoracic duct, with equilibration of IgG derived from SCIG into the intravascular space requiring up to $72 \mathrm{~h}$ [96]. The peak serum $\operatorname{IgG}$ concentration achieved with SCIG is, on average, $61 \%$ of the peak achieved with intravenous infusions of the same dose [99]. This probably accounts for the fewer adverse events compared with IVIG. With weekly SCIG, only a few days elapse between the peak serum level from 1 intravenous dose and administration of the next subcutaneous dose; this clearly obviates the low "trough" serum IgG levels experienced 3-4 weeks after a large bolus of IVIG [100]. Of interest, pooled data have shown that serum IgG levels are higher by $10-20 \%$ (mean $13 \%$ ) with weekly SCIG compared with monthly IVIG [96]. After 6-12 weekly infusions, SCIG results in near steady-state IgG levels, with peak trough differences only about $5 \%$ of the overall mean. In contrast, with IVIG the trough-to-peak difference is often $>100 \%$ of the overall mean. With the weekly SCIG, the levels of IgG at 7-10 days is the same as the one achieved by IVIG in that period; however, the difference is that with IVIG the IgG drops thereafter while with SCIG it remains constant, indicating a good means of sustaining response. Whether these interesting kinetics translate into the same degree of efficacy of SCIG as that of IVIG in the treatment of autoimmune neurological disorders is currently being explored within controlled trials.

\section{IVIG Therapy: Practical Issues}

\section{Administration}

As discussed earlier, the therapeutic dose of IVIG is empirically set at $2 \mathrm{~g} / \mathrm{kg}$, as originally applied by Imbach et al. [1]. This dose is given over $2-5$ days, and followed by a maintenance dose of 1-2 g/kg every 3-4 weeks; although the majority of clinicians prefer to infuse the total dose over 2 days and most studies have used this formula, in older people and those with impaired renal or cardiovascular function it is prudent to administer the dose over 3-5 days.

\section{Adverse Reactions}

\section{Common Infusion-related Reactions}

These are usually minor and occur in not more than $10 \%$ of patients. The most common include mild-to-moderate headache that responds to nonsteroidal anti-inflammatory medications, fever, chills, myalgia, and chest or back pain that occur during the first few hours of the infusion and usually respond by stopping the infusion for $30 \mathrm{~min}$ and resuming it at a slower rate. Postinfusion fatigue, fever, or nausea may also occur and last for up to $24 \mathrm{~h}$. In a large retrospective evidence-based study of all trials performed in neuromuscular disorders, headaches occurred in $16.6 \%$ of patients, fever in $6.6 \%$, hypertension in $4.6 \%$, chills in $3.3 \%$, and nausea in $3.2 \%$ [101].

\section{Rare, More Serious Reactions}

Rare, more serious reactions include thromboembolic events, such as strokes, pulmonary embolism, or myocardial infarction [102-107]. Patients with recent deep vein thrombosis, or immobilized patients who may have a subclinical thrombosis, may be at higher risk. The main causative factor may be an increase in serum viscosity, especially in patients with risk factors, such as cryoglobulinemia, hypercholesterolemia, or hypergammaglobulinemia [106]. A reversible cerebral vasospasm has also been noted [108].

Severe headache due to aseptic meningitis can also be seen. This is unrelated to the proprietary product, the rate of infusion, or the underlying disease [73, 95, 109, 110]. Prophylaxis with intravenous steroids can be occasionally helpful. The symptoms respond to strong analgesia and subside in $24-48 \mathrm{~h}$. Additional diagnostic testing is rarely necessary $[109,110]$. The occurrence of aseptic meningitis is higher in migrainous patients [95], and IVIG may also trigger a migraine attack in patients with a prior history of migraines.

Skin reactions can develop 2-5 days after the infusions and may last up to 30 days. They include urticaria, lichenoid cutaneous lesions, pruritus of the palms, and petechiae of the extremities [73, 109, 111]; they have occurred in 7 of the 120 patients we have serially treated $[73,109,111]$.

Rare anaphylactic reaction due to absence or severe deficiency of IgA in patients who also have anti-IgA antibodies, rarely seen in patients with common variable immunodeficiency, can occur [112]. IgA deficiency is common in the general population (prevalence $\sim 1: 1000$ ), but it is asymptomatic and not a risk factor by itself; about $29 \%$ of these individuals have anti-IgA antibodies but the presence of these antibodies does not necessarily predict the development of allergic reaction to IVIG [113]. 
Acute renal tubular necrosis, mostly reversible, may rarely occur in patients with pre-existing kidney disease and volume depletion, especially the elderly and those with diabetes or poor hydration. It is more often associated with the high concentration of sucrose in some proprietary IVIG products. Osmotically induced tubular injury and vacuolization are the common histopathological findings upon renal biopsy. It is usually reversible, but rare fatalities have been noted. Is should be noted that serum creatinine may rise 1-10 days after the infusion but returns to baseline within 2-60 days of discontinuation. In patients with preexisting kidney disease, close monitoring of creatinine and blood urea nitrogen are essential, while slowing the rate of infusion or selecting products with low osmolality minimizes that risk.

Laboratory Abnormalities After IVIG therapy, the erythrocyte sedimentation rate increases 6-fold owing to enhanced rouleux formation and reduced surface area caused by the infused gamma globulin [111, 114]. This false increase can persist for 2-3 weeks, and should not be considered a sign of a developing vasculitis. Hyponatremia, as low as $130 \mathrm{mg} /$ 1 (normal 135-145 mg/l), after IVIG therapy can be detected. This is also due to the assay method used to measure $\mathrm{Na}^{+}$because additional dilution of the sample is required owing to the high serum protein concentration that follows IVIG infusion. A mild and inconsequential leukopenia can be also observed.

\section{Differences in Products and Pharmacoeconomics}

Among the various IVIG preparations on the market, there is no documented evidence that one is more efficacious than the other for a given disorder. Their cost is also similar. However, some products may be preferable for highrisk patients because these products are low in osmolality, sodium, or sucrose, and presumably have fewer side effects in high-risk patients [3]. Although, IVIG is considered safe for long-term administration, compared with other effective therapeutic modalities such as PE, corticosteroids, or immunosuppressants used in autoimmune neuromuscular disorders, there are no comparative long-term data. The same also applies to pharmacoeconomics, where no long-term comparative studies between these therapies have been performed, except for some limited data being obtained for CIDP [115].

\section{Future Prospects}

Evidence from controlled clinical trials has established IVIG as a first-line therapy for GBS, CIDP, and MMN.
IVIG might be considered as short-term therapy for moderate-to-severe and worsening $\mathrm{MG}$, and it is effective as second-line therapy for treating patients with dermatomyositis, stiff-person syndrome and Lambert-Eaton myasthenic syndrome. The therapeutic benefit of IVIG is short lived and probably explained by the half-life of IgG molecules in vivo. Evolving studies are now exploring the effects and superiority of subcutaneous IgG compared with IVIG in chronic maintenance therapy once induction benefit has been established with IVIG. As with other immunomodulatory treatments, a subset of patients does not benefit from IVIG therapy and, at present, we are unable to predict which patients will respond to IVIG. Thus, surrogate parameters that could predict from the outset which patients are more likely to respond are needed. Progress towards this goal is profiling expression levels of Fc $\gamma$ receptors. Expression of the inhibitory Fc $\gamma$ RIIB on B cells and myeloid cells is impaired in patients with CIDP, but upregulated following clinically effective IVIG therapy [21, 116]. Upregulation of the Fc $\gamma$ RIIB is also observed in animal models of autoimmune disease conditions following effective IVIG treatment [30, 117]. In addition, single nucleotide polymorphisms from genes encoding for the transient axonal glycoprotein 1 and the C-type lectin domain family 10 , member $\mathrm{A}$ are reported to be associated with the clinical outcome of IVIG therapy in patients with CIDP [51]. These candidate biomarkers require validation in larger cohorts and it will be useful to implement a biomarker identification and validation component to define therapeutic responses to IVIG in future clinical trials.

The demand for IVIG therapy is ever-growing but its availability is limited, resulting in supply shortages. Thus, the development of a possible replacement for IVIG in the form of a recombinant product, even if only for a particular disease, would have a major effect. Several companies are currently working towards developing IVIG replacements based on a variety of critical pathways targeted by IVIG therapy. Such developments include recombinant antibodies blocking neonatal Fc receptors for the reduction of autoantibody half-lives, multimeric IgG Fc preparations that block immune complex binding to activating Fc $\gamma$ receptors, and IVIG preparations with enhanced levels of antiinflammatory sialic acid-rich IgG glycovariants. Such replacement therapies might not be effective in all IVIGresponsive autoimmune diseases as they target more specific disease mechanisms than intact native IVIG, while many conditions that respond to IVIG therapy have differing pathological profiles. Clinical studies are therefore needed to evaluate which of the aforementioned recombinant IVIG replacements is effective and for which type of autoimmune disease. In addition, advances in our understanding of how IVIG exerts its beneficial effects in specific neurological diseases might also enable us to develop novel therapeutics 
with immunomodulatory activities similar to those of native IgG for targeted immunotherapeutic interventions.

Acknowledgments Isaak Quast was supported by a DOC scholarship provided by the Austrian Academy of Sciences.

Required Author Forms Disclosure forms provided by the authors are available with the online version of this article.

\section{References}

1. Imbach P, Barandun S, d'Apuzzo V, et al. High-dose intravenous gammaglobulin for idiopathic thrombocytopenic purpura in childhood. Lancet 1981;1:1228-1231.

2. Fehr J, Hofmann V, Kappeler U. Transient reversal of thrombocytopenia in idiopathic thrombocytopenic purpura by high-dose intravenous gamma globulin. N Engl J Med 1982;306:1254-1258.

3. Gelfand EW. Intravenous immune globulin in autoimmune and inflammatory diseases. N Engl J Med 2012;367:2015-2025.

4. Lunemann JD, Nimmerjahn F, Dalakas MC. Intravenous immunoglobulin in neurology-mode of action and clinical efficacy. Nat Rev Neurol 2015;11:80-89.

5. Boruchov AM, Heller G, Veri MC, Bonvini E, Ravetch JV, Young JW. Activating and inhibitory IgG Fc receptors on human DCs mediate opposing functions. J Clin Invest 2005;115:2914-2923.

6. Yuasa T, Kubo S, Yoshino T, et al. Deletion of fcgamma receptor IIB renders H-2(b) mice susceptible to collagen-induced arthritis. J Exp Med 1999;189:187-194.

7. Daeron M, Latour S, Malbec O, et al. The same tyrosine-based inhibition motif, in the intracytoplasmic domain of $\mathrm{Fc}$ gamma RIIB, regulates negatively BCR-, TCR-, and FcR-dependent cell activation. Immunity 1995;3:635-646.

8. Xiang Z, Cutler AJ, Brownlie RJ, et al. FcgammaRIIb controls bone marrow plasma cell persistence and apoptosis. Nat Immunol 2007;8:419-429.

9. Fukuyama H, Nimmerjahn F, Ravetch JV. The inhibitory Fcgamma receptor modulates autoimmunity by limiting the accumulation of immunoglobulin $\mathrm{G}+$ anti-DNA plasma cells. Nat Immunol 2005;6:99-106.

10. Ober RJ, Martinez C, Vaccaro C, Zhou J, Ward ES. Visualizing the site and dynamics of IgG salvage by the MHC class I-related receptor, FcRn. J Immunol 2004;172:2021-2029.

11. Chaudhury C, Mehnaz S, Robinson JM, et al. The major histocompatibility complex-related $\mathrm{Fc}$ receptor for $\mathrm{IgG}(\mathrm{FcRn})$ binds albumin and prolongs its lifespan. J Exp Med 2003;197:315-322.

12. Dickinson BL, Badizadegan $\mathrm{K}, \mathrm{Wu} \mathrm{Z}$, et al. Bidirectional FcRndependent $\operatorname{IgG}$ transport in a polarized human intestinal epithelial cell line. J Clin Invest 1999;104:903-911.

13. Viard I, Wehrli P, Bullani R, et al. Inhibition of toxic epidermal necrolysis by blockade of CD95 with human intravenous immunoglobulin. Science 1998;282:490-493.

14. Rossi F, Kazatchkine MD. Antiidiotypes against autoantibodies in pooled normal human polyspecific Ig. J Immunol 1989;143:41044109.

15. Shoenfeld Y, Rauova L, Gilburd B, et al. Efficacy of IVIG affinitypurified anti-double-stranded DNA anti-idiotypic antibodies in the treatment of an experimental murine model of systemic lupus erythematosus. Int Immunol 2002;14:1303-1311.

16. Fuchs S, Feferman T, Meidler R, et al. A disease-specific fraction isolated from IVIG is essential for the immunosuppressive effect of IVIG in experimental autoimmune myasthenia gravis. J Neuroimmunol 2008;194:89-96.
17. Buchwald B, Ahangari R, Weishaupt A, Toyka KV. Intravenous immunoglobulins neutralize blocking antibodies in Guillain-Barré syndrome. Ann Neurol 2002;51:673-680.

18. Marchalonis JJ, Kaymaz H, Dedeoglu F, Schluter SF, Yocum DE, Edmundson AB. Human autoantibodies reactive with synthetic autoantigens from T-cell receptor beta chain. Proc Natl Acad Sci U S A 1992;89:3325-3329.

19. Debre M, Bonnet MC, Fridman WH, et al. Infusion of $\mathrm{Fc}$ gamma fragments for treatment of children with acute immune thrombocytopenic purpura. Lancet 1993;342:945-949.

20. Nagelkerke SQ, Dekkers G, Kustiawan I, et al. Inhibition of FcgammaR-mediated phagocytosis by IVIg is independent of IgG-Fc sialylation and FcgammaRIIb in human macrophages. Blood 2014; 124:3709-3718.

21. Tackenberg B, Jelcic I, Baerenwaldt A, et al. Impaired inhibitory Fcgamma receptor IIB expression on B cells in chronic inflammatory demyelinating polyneuropathy. Proc Natl Acad Sci U S A 2009;106:4788-4792.

22. Samuelsson A, Towers TL, Ravetch JV. Anti-inflammatory activity of IVIG mediated through the inhibitory Fc receptor. Science 2001;291:484-486.

23. Hansen RJ, Balthasar JP. Intravenous immunoglobulin mediates an increase in anti-platelet antibody clearance via the FcRn receptor. Thromb Haemost 2002;88:898-899.

24. Kondo N, Kasahara K, Kameyama T, et al. Intravenous immunoglobulins suppress immunoglobulin productions by suppressing $\mathrm{Ca}(2+)$-dependent signal transduction through $\mathrm{Fc}$ gamma receptors in B lymphocytes. Scand J Immunol 1994;40:37-42.

25. Anthony RM, Kobayashi T, Wermeling F, Ravetch JV. Intravenous gammaglobulin suppresses inflammation through a novel T(H)2 pathway. Nature 2011;475:110-113.

26. Mollnes TE, Hogasen K, Hoaas BF, Michaelsen TE, Garred P, Harboe M. Inhibition of complement-mediated red cell lysis by immunoglobulins is dependent on the IG isotype and its $\mathrm{C} 1$ binding properties. Scand J Immunol 1995;41:449-456.

27. Quast I, Keller CW, Maurer MA, Giddens JP, Tackenberg B, Wang LX, Münz C, Nimmerjahn F, Dalakas MC, Lünemann JD. Sialylation of IgG Fc domain impairs complementdependent cytotoxicity. J Clin Invest 2015; in press.

28. De Groot AS, Moise L, McMurry JA, et al. Activation of natural regulatory T cells by IgG Fc-derived peptide "Tregitopes". Blood 2008;112:3303-3311.

29. Bayry J, Lacroix-Desmazes S, Carbonneil C, et al. Inhibition of maturation and function of dendritic cells by intravenous immunoglobulin. Blood 2003;101:758-765.

30. Kaneko Y, Nimmerjahn F, Ravetch JV. Anti-inflammatory activity of immunoglobulin $\mathrm{G}$ resulting from Fc sialylation. Science 2006;313:670-673.

31. Anthony RM, Nimmerjahn F, Ashline DJ, Reinhold VN, Paulson JC, Ravetch JV. Recapitulation of IVIG antiinflammatory activity with a recombinant $\operatorname{IgG}$ Fc. Science 2008;320:373-376.

32. Schwab I, Mihai S, Seeling M, Kasperkiewicz M, Ludwig RJ, Nimmerjahn F. Broad requirement for terminal sialic acid residues and FcgammaRIIB for the preventive and therapeutic activity of intravenous immunoglobulins in vivo. Eur J Immunol 2014;44: 1444-1453.

33. Leontyev D, Katsman Y, Ma XZ, Miescher S, Kasermann F, Branch DR. Sialylation-independent mechanism involved in the amelioration of murine immune thrombocytopenia using intravenous gammaglobulin. Transfusion 2012;52:1799-1805.

34. Leontyev D, Katsman Y, Branch DR. Mouse background and IVIG dosage are critical in establishing the role of inhibitory Fcgamma receptor for the amelioration of experimental ITP. Blood 2012;119:5261-5264. 
35. Othy S, Topcu S, Saha C, et al. Sialylation may be dispensable for reciprocal modulation of helper $\mathrm{T}$ cells by intravenous immunoglobulin. Eur J Immunol 2014;44:2059-2063.

36. Dalakas MC, Medscape. Advances in the diagnosis, pathogenesis and treatment of CIDP. Nat Rev Neurol 2011;7:507-517.

37. van der Meche FG, Schmitz PI. A randomized trial comparing intravenous immune globulin and plasma exchange in GuillainBarré syndrome. Dutch Guillain-Barré Study Group. N Engl J Med 1992;326:1123-1129.

38. Plasma Exchange/Sandoglobulin Guillain-Barré Syndrome Trial Group. Randomised trial of plasma exchange, intravenous immunoglobulin, and combined treatments in Guillain-Barré syndrome. Lancet 1997;349:225-230.

39. El-Bayoumi MA, El-Refaey AM, Abdelkader AM, El-Assmy MM, Alwakeel AA, El-Tahan HM. Comparison of intravenous immunoglobulin and plasma exchange in treatment of mechanically ventilated children with Guillain Barré syndrome: a randomized study. Crit Care 2011;15:R164.

40. Farcas P, Avnun L, Frisher S, Herishanu YO, Wirguin I. Efficacy of repeated intravenous immunoglobulin in severe unresponsive Guillain-Barré syndrome. Lancet 1997;350:1747.

41. Kuitwaard K, de Gelder J, Tio-Gillen AP, et al. Pharmacokinetics of intravenous immunoglobulin and outcome in Guillain-Barré syndrome. Ann Neurol 2009;66:597-603.

42. Hughes R, Bensa S, Willison H, et al. Randomized controlled trial of intravenous immunoglobulin versus oral prednisolone in chronic inflammatory demyelinating polyradiculoneuropathy. Ann Neurol 2001;50:195-201.

43. Dyck PJ, Litchy WJ, Kratz KM, et al. A plasma exchange versus immune globulin infusion trial in chronic inflammatory demyelinating polyradiculoneuropathy. Ann Neurol 1994;36:838-845.

44. Mendell JR, Barohn RJ, Freimer ML, et al. Randomized controlled trial of IVIg in untreated chronic inflammatory demyelinating polyradiculoneuropathy. Neurology 2001;56:445-449.

45. Hughes RA, Donofrio P, Bril V, et al. Intravenous immune globulin ( $10 \%$ caprylate-chromatography purified) for the treatment of chronic inflammatory demyelinating polyradiculoneuropathy (ICE study): a randomised placebo-controlled trial. Lancet Neurol 2008;7:136-144.

46. Merkies IS, Bril V, Dalakas MC, et al. Health-related quality-oflife improvements in CIDP with immune globulin IV $10 \%$ : the ICE Study. Neurology 2009;72:1337-1344.

47. Bril V, Katzberg H, Donofrio P, et al. Electrophysiology in chronic inflammatory demyelinating polyneuropathy with IGIV. Muscle Nerve 2009;39:448-455.

48. Latov N, Deng C, Dalakas MC, et al. Timing and course of clinical response to intravenous immunoglobulin in chronic inflammatory demyelinating polyradiculoneuropathy. Arch Neurol 2010;67: 802-807.

49. Vermeulen M, van Doorn PA, Brand A, Strengers PF, Jennekens $\mathrm{FG}$, Busch HF. Intravenous immunoglobulin treatment in patients with chronic inflammatory demyelinating polyneuropathy: a double blind, placebo controlled study. J Neurol Neurosurg Psychiatry 1993;56:36-39.

50. Hahn AF, Bolton CF, Pillay N, et al. Plasma-exchange therapy in chronic inflammatory demyelinating polyneuropathy. A doubleblind, sham-controlled, cross-over study. Brain 1996;119:10551066.

51. Iijima M, Tomita M, Morozumi S, et al. Single nucleotide polymorphism of TAG-1 influences IVIg responsiveness of Japanese patients with CIDP. Neurology 2009;73:1348-1352.

52. Chaudhry V, Corse AM, Cornblath DR, et al. Multifocal motor neuropathy: response to human immune globulin. Ann Neurol 1993;33:237-242.

53. Federico P, Zochodne DW, Hahn AF, Brown WF, Feasby TE. Multifocal motor neuropathy improved by IVIg: randomized, double-blind, placebo-controlled study. Neurology 2000;55: 1256-1262.

54. Van den Berg-Vos RM, Franssen H, Wokke JH, Van den Berg LH. Multifocal motor neuropathy: long-term clinical and electrophysiological assessment of intravenous immunoglobulin maintenance treatment. Brain 2002;125:1875-1886.

55. Dalakas MC, Quarles RH, Farrer RG, et al. A controlled study of intravenous immunoglobulin in demyelinating neuropathy with IgM gammopathy. Ann Neurol 1996;40:792-795.

56. Comi G, Roveri L, Swan A, et al. A randomised controlled trial of intravenous immunoglobulin in IgM paraprotein associated demyelinating neuropathy. J Neurol 2002;249:1370-1377.

57. Jann S, Bramerio MA, Facchetti D, Sterzi R. Intravenous immunoglobulin is effective in patients with diabetes and with chronic inflammatory demyelinating polyneuropathy: long term followup. J Neurol Neurosurg Psychiatry 2009;80:70-73.

58. Kawagashira Y, Watanabe H, Morozumi S, et al. Differential response to intravenous immunoglobulin (IVIg) therapy among multifocal and polyneuropathy types of painful diabetic neuropathy. J Clin Neurosci 2010;17:1003-1008.

59. Levy Y, Uziel Y, Zandman G, et al. Response of vasculitic peripheral neuropathy to intravenous immunoglobulin. Ann N Y Acad Sci 2005;1051:779-786.

60. Rist S, Sellam J, Hachulla E, et al. Experience of intravenous immunoglobulin therapy in neuropathy associated with primary Sjogren's syndrome: a national multicentric retrospective study. Arthritis Care Res (Hoboken) 2011;63:1339-1344.

61. Gajdos P, Chevret S, Clair B, Tranchant C, Chastang C. Clinical trial of plasma exchange and high-dose intravenous immunoglobulin in myasthenia gravis. Myasthenia Gravis Clinical Study Group. Ann Neurol 1997;41:789-796.

62. Gajdos P, Tranchant C, Clair B, et al. Treatment of myasthenia gravis exacerbation with intravenous immunoglobulin: a randomized double-blind clinical trial. Arch Neurol 2005;62:1689-1693.

63. Zinman L, Ng E, Bril V. IV immunoglobulin in patients with myasthenia gravis: a randomized controlled trial. Neurology 2007;68:837-841.

64. Gajdos P, Chevret S, Toyka K. Intravenous immunoglobulin for myasthenia gravis. Cochrane Database Syst Rev 2008;CD002277.

65. Bain PG, Motomura M, Newsom-Davis J, et al. Effects of intravenous immunoglobulin on muscle weakness and calciumchannel autoantibodies in the Lambert-Eaton myasthenic syndrome. Neurology 1996;47:678-683.

66. Dalakas MC, Illa I, Dambrosia JM, et al. A controlled trial of highdose intravenous immune globulin infusions as treatment for dermatomyositis. N Engl J Med 1993;329:1993-2000.

67. Basta M, Dalakas MC. High-dose intravenous immunoglobulin exerts its beneficial effect in patients with dermatomyositis by blocking endomysial deposition of activated complement fragments. J Clin Invest 1994;94:1729-1735.

68. Dalakas MC. Controlled studies with high-dose intravenous immunoglobulin in the treatment of dermatomyositis, inclusion body myositis, and polymyositis. Neurology 1998;51(6 Suppl. 5):S37S45.

69. Amemiya K, Semino-Mora C, Granger RP, Dalakas MC. Downregulation of TGF-betal mRNA and protein in the muscles of patients with inflammatory myopathies after treatment with high-dose intravenous immunoglobulin. Clin Immunol 2000;94: 99-104.

70. Raju R, Dalakas MC. Gene expression profile in the muscles of patients with inflammatory myopathies: effect of therapy with IVIg and biological validation of clinically relevant genes. Brain 2005;128:1887-1896.

71. Kampylafka EI, Kosmidis ML, Panagiotakos DB, Dalakas M, Moutsopoulos HM, Tzioufas AG. The effect of intravenous 
immunoglobulin (IVIG) treatment on patients with dermatomyositis: a 4-year follow-up study. Clin Exp Rheumatol 2012;30:397401

72. Wang DX, Shu XM, Tian XL, et al. Intravenous immunoglobulin therapy in adult patients with polymyositis/dermatomyositis: a systematic literature review. Clin Rheumatol 2012;31:801-806.

73. Dalakas MC, Sonies B, Dambrosia J, Sekul E, Cupler E, Sivakumar K. Treatment of inclusion-body myositis with IVIg: a double-blind, placebo-controlled study. Neurology 1997;48: 712-716.

74. Walter MC, Lochmuller H, Toepfer M, et al. High-dose immunoglobulin therapy in sporadic inclusion body myositis: a doubleblind, placebo-controlled study. J Neurol 2000;247:22-28.

75. Dalakas MC, Koffman B, Fujii M, Spector S, Sivakumar K, Cupler E. A controlled study of intravenous immunoglobulin combined with prednisone in the treatment of IBM. Neurology 2001;56:323-327.

76. Zschuntzsch J, Voss J, Creus K, et al. Provision of an explanation for the inefficacy of immunotherapy in sporadic inclusion body myositis: quantitative assessment of inflammation and betaamyloid in the muscle. Arthritis Rheum 2012;64:4094-4103.

77. Dalakas MC, Fujii M, Li M, McElroy B. The clinical spectrum of anti-GAD antibody-positive patients with stiff-person syndrome. Neurology 2000;55:1531-1535.

78. Dalakas MC, Fujii M, Li M, Lutfi B, Kyhos J, McElroy B. Highdose intravenous immune globulin for stiff-person syndrome. $\mathrm{N}$ Engl J Med 2001;345:1870-1876.

79. Fazekas F, Deisenhammer F, Strasser-Fuchs S, Nahler G, Mamoli B. Randomised placebo-controlled trial of monthly intravenous immunoglobulin therapy in relapsing-remitting multiple sclerosis. Austrian Immunoglobulin in Multiple Sclerosis Study Group. Lancet 1997;349:589-593.

80. Achiron A, Gabbay U, Gilad R, et al. Intravenous immunoglobulin treatment in multiple sclerosis. Effect on relapses. Neurology 1998;50:398-402.

81. Sorensen PS, Haas J, Sellebjerg F, Olsson T, Ravnborg M, Group TS. IV immunoglobulins as add-on treatment to methylprednisolone for acute relapses in MS. Neurology 2004;63:2028-2033.

82. Visser LH, Beekman R, Tijssen CC, et al. A randomized, doubleblind, placebo-controlled pilot study of i.v. immune globulins in combination with i.v. methylprednisolone in the treatment of relapses in patients with MS. Mult Scler 2004;10:89-91.

83. Fazekas F, Lublin FD, Li D, et al. Intravenous immunoglobulin in relapsing-remitting multiple sclerosis: a dose-finding trial. Neurology 2008;71:265-271.

84. Hommes OR, Sorensen PS, Fazekas F, et al. Intravenous immunoglobulin in secondary progressive multiple sclerosis: randomised placebo-controlled trial. Lancet 2004;364:1149-1156.

85. Achiron A, Kishner I, Dolev M, et al. Effect of intravenous immunoglobulin treatment on pregnancy and postpartum-related relapses in multiple sclerosis. J Neurol 2004;251:1133-1137.

86. Haas J, Hommes OR. A dose comparison study of IVIG in postpartum relapsing-remitting multiple sclerosis. Mult Scler 2007;13: 900-908.

87. Elsone L, Panicker J, Mutch K, Boggild M, Appleton R, Jacob A. Role of intravenous immunoglobulin in the treatment of acute relapses of neuromyelitis optica: experience in 10 patients. Mult Scler 2014;20:501-504.

88. Magraner MJ, Coret F, Casanova B. The effect of intravenous immunoglobulin on neuromyelitis optica. Neurologia 2013;28: 65-72.

89. Titulaer MJ, McCracken L, Gabilondo I, et al. Treatment and prognostic factors for long-term outcome in patients with antiNMDA receptor encephalitis: an observational cohort study. Lancet Neurol 2013;12:157-165.
90. Dalakas MC. Pathogenetic mechanisms of post-polio syndrome: morphological, electrophysiological, virological, and immunological correlations. Ann N Y Acad Sci 1995;753:167-185.

91. Gonzalez H, Sunnerhagen KS, Sjoberg I, Kaponides G, Olsson T, Borg K. Intravenous immunoglobulin for post-polio syndrome: a randomised controlled trial. Lancet Neurol 2006;5:493-500.

92. Goebel A, Baranowski A, Maurer K, Ghiai A, McCabe C, Ambler G. Intravenous immunoglobulin treatment of the complex regional pain syndrome: a randomized trial. Ann Intern Med 2010;152: 152-158.

93. Markvardsen LH, Harbo T, Sindrup SH, et al. Subcutaneous immunoglobulin preserves muscle strength in chronic inflammatory demyelinating polyneuropathy. Eur J Neurol 2014;21:1465-1470.

94. Vlam L, Cats EA, Willemse E, et al. Pharmacokinetics of intravenous immunoglobulin in multifocal motor neuropathy. J Neurol Neurosurg Psychiatry 2014;85:1145-1148.

95. Sekul EA, Cupler EJ, Dalakas MC. Aseptic meningitis associated with high-dose intravenous immunoglobulin therapy: frequency and risk factors. Ann Intern Med 1994;121:259-262.

96. Berger M, Allen JA. Optimizing IgG therapy in chronic autoimmune neuropathies: a hypothesis driven approach. Muscle Nerve 2015;51:315-326.

97. Roopenian DC, Akilesh S. FcRn: the neonatal Fc receptor comes of age. Nat Rev Immunol 2007;7:715-725.

98. Yu Z, Lennon VA. Mechanism of intravenous immune globulin therapy in antibody-mediated autoimmune diseases. N Engl J Med 1999;340:227-228.

99. Berger M. Choices in IgG replacement therapy for primary immune deficiency diseases: subcutaneous IgG vs. intravenous IgG and selecting an optimal dose. Curr Opin Allergy Clin Immunol 2011;11:532-538.

100. Berger M, Rojavin M, Kiessling P, Zenker O. Pharmacokinetics of subcutaneous immunoglobulin and their use in dosing of replacement therapy in patients with primary immunodeficiencies. Clin Immunol 2011;139:133-141.

101. Patwa HS, Chaudhry V, Katzberg H, Rae-Grant AD, So YT. Evidence-based guideline: intravenous immunoglobulin in the treatment of neuromuscular disorders: report of the Therapeutics and Technology Assessment Subcommittee of the American Academy of Neurology. Neurology 2012;78:1009-1015.

102. Woodruff RK, Grigg AP, Firkin FC, Smith IL. Fatal thrombotic events during treatment of autoimmune thrombocytopenia with intravenous immunoglobulin in elderly patients. Lancet 1986;2: 217-218.

103. Hague RA, Eden OB, Yap PL, Mok JY, Rae P. Hyperviscosity in HIV infected children-a potential hazard during intravenous immunoglobulin therapy. Blut 1990;61:66-67.

104. Schiff RI. Intravenous gammaglobulin, 2: Pharmacology, clinical uses and mechanisms of action. Pediatr Allergy Immunol 1994;5: 127-156.

105. Schiff RI. Intravenous gammaglobulin: pharmacology, clinical uses and mechanisms of action. Pediatr Allergy Immunol 1994;5:63-87.

106. Dalakas MC. High-dose intravenous immunoglobulin and serum viscosity: risk of precipitating thromboembolic events. Neurology 1994:44:223-226.

107. Dalakas MC, Clark WM. Strokes, thromboembolic events, and IVIg: rare incidents blemish an excellent safety record. Neurology 2003;60:1736-1737.

108. Voltz R, Rosen FV, Yousry T, Beck J, Hohlfeld R. Reversible encephalopathy with cerebral vasospasm in a Guillain-Barré syndrome patient treated with intravenous immunoglobulin. Neurology 1996;46:250-251.

109. Dalakas MC. Intravenous immune globulin therapy for neurologic diseases. Ann Intern Med 1997;126:721-730. 
110. Dalakas MC. Update on the use of intravenous immune globulin in the treatment of patients with inflammatory muscle disease. $\mathrm{J}$ Clin Immunol 1995;15(6 Suppl.):70S-75S.

111. Dalakas MC. Intravenous immunoglobulin in the treatment of autoimmune neuromuscular diseases: present status and practical therapeutic guidelines. Muscle Nerve 1999;22:1479-1497.

112. Bjorkander J, Hammarstrom L, Smith CI, Buckley RH, Cunningham-Rundles C, Hanson LA. Immunoglobulin prophylaxis in patients with antibody deficiency syndromes and anti-IgA antibodies. J Clin Immunol 1987;7:8-15.

113. Burks AW, Sampson HA, Buckley RH. Anaphylactic reactions after gamma globulin administration in patients with hypogammaglobulinemia. Detection of IgE antibodies to IgA. N Engl J Med 1986;314:560-564.
114. Koffman BM, Dalakas MC. Effect of high-dose intravenous immunoglobulin on serum chemistry, hematology, and lymphocyte subpopulations: assessments based on controlled treatment trials in patients with neurological diseases. Muscle Nerve 1997;20: 1102-1107.

115. McCrone P, Chisholm D, Knapp M, et al. Cost-utility analysis of intravenous immunoglobulin and prednisolone for chronic inflammatory demyelinating polyradiculoneuropathy. Eur J Neurol 2003; 10:687-694.

116. Quast I, Cueni F, Nimmerjahn F, Tackenberg B, Lunemann JD. Deregulated Fc $\gamma$ Receptor Expression in Patients with CIDP. Neurol Neuroimmunol Neuroinflamm 2015; in press.

117. Schwab I, Nimmerjahn F. Intravenous immunoglobulin therapy: how does IgG modulate the immune system? Nat Rev Immunol 2013;13:176-189. 